\title{
Yansıma Dergisinde Sabahattin Ali ve Nâzım Hikmet*
}

\author{
Sabahattin Ali and Nâzım Hikmet at Journal of Yansıma
}

\author{
Ali PULAT $T^{* *}$ \\ Keziban KARAARSLAN $N^{* * * *}$
}

Özet

$\mathrm{Bu}$ çalışmanın konusu, Yansıma dergisi ve bu dergide Sabahattin Ali ve Nâzım Hikmet üzerine yapılmış olan edebî faaliyetlerdir. Yansıma, Ocak 1972 ile Eylül 1975 tarihleri arasında Tekin Sönmez'in öncülüğünde aylık olarak toplam 45 sayı çıkan bir sanat ve kültür dergisidir. Yaklaşık dört y1llık yayın hayatı boyunca derginin bünyesinde önemli çalışmalara imza atılmıştır. Bunlardan biri Mart 1973 tarihinde Sabahattin Ali adına çıkarılış olan "25. Ölüm Y1ldönümünde Sabahattin Ali Özel Sayısı"; diğeri Haziran 1974 tarihinde Nâzım Hikmet adına çıkarılmış olan "Nâzım Hikmet Özel Sayısı"dir.

Çalı̧̧mamızda, öncelikle Yansıma dergisinin genel bir tanıtımı yapılacak ardından gerek adı geçen özel sayılarda gerek diğer sayılarda yer alan Sabahattin Ali ve Nâzım Hikmet hakkındaki yazılar incelenecektir.

Anahtar Kelimeler: Dergi, Yansima, Sabahattin Ali, Nâzım Hikmet

\begin{abstract}
The subject of this study is the journal of Yansima and literary activities carried out on Sabahattin Ali and Nâzım Hikmet. Yansıma is an art and culture magazine which had monthly 45 releases between January 1972 and September 1975 under the leadership of Tekin Sönmez. During the nearly four years of its publishing life, many important works had been produced in the magazine. One of them is "Sabahattin Ali Special Number on the 25th Death Anniversary" issued on behalf of Sabahattin Ali on March 1973, and the other one is "Special Number of Nâzım Hikmet" issued on behalf of Nâzım Hikmet on June 1974.

In our work, first a general introduction of the journal of Yansima will be made and then the writings about Nazım Hikmet and Sabahattin Ali in the special releases mentioned above and other releases will be analysed.
\end{abstract}

Keywords: Journal, Yansima, Sabahattin Ali, Nâzım Hikmet

* Bu çalışma, 5-8 Ekim 2017 tarihleri arasında Kırıkkale Üniversitesi tarafından düzenlenen 1. Uluslararası Bilimsel ve Mesleki Çalışmalar Kongresi (BILMES 2017)'nde sözlü olarak sunulan bildirinin genişletilmiş şeklidir.

** Yrd. Doç. Dr. Uşak Üniversitesi, Fen Edebiyat Fakültesi, Türk Dili ve Edebiyatı Bölümü Öğretim Üyesi. e posta: ali.pulat@usak.edu.tr

*** Uşak Üniversitesi, Sosyal Bilimler Enstitüsü, Türk Dili ve Edebiyatı Anabilim Dalı Doktora Öğrencisi. e posta: kezban88@outlook.com 


\section{Giriş: Yansıma Dergisi}

Yansıma, Ocak 1972 ile Eylül 1975 tarihleri arasında genelde altmış dört sayfalık bir dergi olarak ayda bir İstanbul'da yayımlanır. Yaklaşık dört yıllık sürede toplam 45 sayı çıkar. İlk otuz sayıda derginin imtiyaz sahibi Tekin Sönmez iken otuz birinci sayıdan kapanıncaya kadar ise Hasan Can'dır. Sorumlu müdürlüğünü üstlenen isimler de sırasıyla M. Ş. Yardım (1-10. sayılar / 12 - 39. sayılar), Mahir Öztaş (11. sayı) ve Ender Kâmil Boyacı (40-45. sayılar aras1)'dir.

16x24 cm ebatlarında olan ve ilk sayılarında biçimsel yönden oldukça sade bir görünüm sergileyen ancak sonraki sayılarının kapak düzeninde değişiklikler yaparak (fotoğraf, resim vb. ekleyerek) dikkatleri üzerine çeken Yansıma, Afet Ilgaz, Ahmet Özer, Arif Damar, Arkadaş Zekai Özger, Behzat Ay, Ceyhun Atuf Kansu, Fakir Baykurt, Füruzan, Hasan Hüseyin Korkmazgil, Muzaffer Buyrukçu, Necati Güngör, Necati Tosuner, Rıfat Ilgaz, Samim Kocagöz, Şükran Kurdakul, Talip Apaydın, Tarık Dursun K. ve Tekin Sönmez gibi isimlerin yer aldığ1 kadroyla şiirden hikâyeye, tiyatrodan sinemaya, karikatüre kadar pek çok sanat dalıyla ilgili önemli çalışmalara imza atmıştır. Böylece gününde ve günümüzde adından söz ettiren bir dergi olmuştur.

Yansıman’nın yaptığı önemli faaliyetlerden biri de çıkardığı özel sayılardır. Bunlar yayım boyunca sekiz tanedir ve sırasıyla şöyledir: Hikâye Özel Sayısı (6. sayı), Vietnam Sanatı Özel Sayısı (10. say1), 25. Ölüm Yıldönümünde Sabahattin Ali Özel Sayısı (15. say1), Günümüz Türk Şiiri Özel Sayısı (18. sayı), Nâzım Hikmet Özel Sayısı (30. sayı), Mizah ve Karikatür Özel Sayısı (33. say1), Kapitalizme ve Faşizme Karşı Asya - Afrika- Güney Amerika'da Şiir Sanatı ve Direniş Şiirleri Özel Sayısı (36. sayı) ve Çocuk Eğitimi ve Edebiyatı Özel Sayısı (43-44-45. say1)'dir.

Toplumcu edebiyatın 1970’li yıllardaki sözcülüğünü üstlendiğini ileri süren derginin, bu edebiyatın kilometre taşlarından olan Sabahattin Ali ve Nâzım Hikmet üzerine sayılar düzenlemesi ve diğer sayılarda da her iki şahsiyete yer vermesi dikkat çeken hususlardan biridir. Dolayısıyla yazımızda gerek bu iki özel sayıda gerekse diğer sayılarda Sabahattin Ali ve Nâzım Hikmet üzerine yazılan çalı̧̧malar incelenerek Yansımảnın bu isimlere yaklaşımı değerlendirilmeye çalışılacaktır.

\section{Yansıma Dergisinde Sabahattin Ali}

Yansıma dergisinde Sabahattin Ali ile ilgili yazıların ağırlıklı olarak 15. sayıda yer aldı̆̆ı görülmektedir. 15. sayı, Sabahattin Ali’nin 25. ölüm yıldönümü münasebetiyle özel sayı olarak yayınlanmıştır. Söz konusu sayının başyazısı, 1923 Türkiye'sinde Ankara'nın çevresini yabancı ve menfaatçi elit bir bürokratik çevrenin sardı̆̆ı ve halkla ayrıştı̆̆ı böylece "halkçılık" ilkesinin ortaya çıktı̆̆ı bir dönemde Sabahattin Ali’yi ve edebiyatçılığını doğru anlamak ve aktarmak mümkündür (Köksal, 1973: 130-132) vurgusu ile çıkar. Bu bakımdan Sabahattin Ali dergide toplumcu yönüyle ele alınır. 
Rıfat Ilgaz, dergideki "25 Yıl Sonra”(1973: 134-143) başlıklı yazısında daha çok hatıralardan bahseder. Sabahattin Ali’nin mütevazı yönü sebebi ile tam anlaşılamadı̆̆ından yakınır. Onu ürkek ve çekingen olarak değerlendirenleri eleştirir. Nâzım Hikmet'in mektubunda ona desteğini, güvenini ifade ederek "Türk hikâye ve romanının tek bayră̆ı sensin.” şeklinde övdüğü bölümden alıntı yapar. $\mathrm{Bu}$ yazı, Sabahattin Ali’nin edebiyat çevrelerince tam anlaşılmadığı kaygısını barındırır ve bunu düzeltmeyi hedefler.

Sabahattin Ali'nin hikâyeciliğini yazan Mehmet Seyda, onun eserlerinde doğa-insan (toplum) uyumu çerçevesinde sağlıklı bir romantizm bulur. Mehmet Seyda, gerçekçilik akımının ustalarından Maupassant, Gorki ve Zola'nın da eserlerinde bu tür duygu öğesini ihmal etmedikleri görüşündedir. Nâzım kimi şiirlerinde lirizmi coşkuya götürmüşse Sabahattin Ali de romantizme ulaşmıştır. Yazıda Sabahattin Ali'nin bir mektubundan alıntı verilmiştir. Mektupta, “..sanat insana insanı ve hayatı ve bunların manasını öğretmekle muvazzaftır.. Sanat bütün teferruatıyla hayatı ihtiva etmeli, daha iyiye ve yükseğe insanca yaşama arzusunu uyandırmalı." ifadelerine yer verir. Sabahattin Ali’ye göre sanat gâye değil vasıtadır; gâye hayattır. Yazıda Eliot'un "Hiçbir sanatçının tek başına bir anlamı yoktur." anlayışından hareketle Sabahattin Ali'nin kendi dönemi içindeki yeri tespit edilmeye çalış1lmış; bu çerçevede en genel manada Sait Faik’in iç gözlemciliğinin, Sabahattin Ali'de de genellikle dış gözlemciliğinin belirgin olduğu (Seyda, 1973: 147-153) söylenmiştir.

Ceyhun Atuf Kansu, yazısında Tahir Alangu'dan bir alıntı yapar: “ ...toplumcu gerçekçiliğe bağlı olduğu yaygındır halbuki bu durum hayatının sonlarına doğru yaşadıklarının sürüklediği bir durumdur. Son hikâyeleri hariç romantik özentilere yer verilen tasvirci gözlemci gerçekçilik basamağından pek ileri geçememiştir.” Yazıda Sabahattin Ali’nin şiirleri de tek sesli, savı ve direnci olmayan, şairin kendi duyarlığını denediği şiirler (Kansu, 1973: 157) olarak nitelendirilir.

Dergide Şükran Kurdakul'un “Sabahattin Ali ve Varlık Dergisi” (1973: 160- 162) başliklı yazısında bir röportajdan alıntılar yapılır. Burada halk ve divan edebiyatından faydalanma konusu gündeme gelir. Sabahattin Ali de halk edebiyatının geri taraflarının ve divan edebiyatının karanlık taraflarının ayıklanmak şartıyla sosyal analiz konusunda yararlanılabileceğini söyler.

Füruzan, dergide Sabahattin Ali'nin "Hanende Melek" adlı hikâyesi hakkında görüşlerini yazmıştır. Füruzan'a göre Sabahattin Ali, hikâyeciliğini her dönemde yaşamış, güncel ve kişisel ilişkilerine hikâyeci kimliğini sindirmiş bir kişiliktir. O, Anadolu'nun edebiyata girmemiş çevrelerini ele almış, o koşulların insanını işleme cephesiyle öncü olmuştur (1973: 163-165/193).

Tekin Sönmez “Ayran” ve "Kağnı” hikâyelerini değerlendirir ve bu hikâyeleri karşılaştırır. Sönmez, Sabahattin Ali’nin üslûbu ile Nâzım'ın şiirde başardığını yapmıştır, (1973: 166-171) görüşündedir. 
Hulki Aktunç (1973: 176-180), İ̧̧imizdeki Şeytan'da dönemin yarı aydın sorunsalının boyutlarının anlatıldığını söyler. Hulki Aktunç'a göre romanın tezi, "bireyin içindeki şeytanın, pasifliğin ve toplumdan uzak düşmenin yanlışlı̆̆ı”nı ortaya koymaktır.

Dergide Kemal Ateş’in yazısı “Sabahattin Alinin Eserlerinde Hapishane” (1973: 181-185) başlığıyla çıkmıştır. Kemal Ateş'e göre hapishane merkezli bir bakış açısı ile halkın yoksulluğu, devletin baskıları ve ekonomik bozuklukların toplumdaki erdemli davranışları yok etmesi anlatılır. Eserlerin teknik açıdan Balzac ve Zola gibi realistlerin "tahminî” realizmi ile değil bizzat yaşanarak ve şahit olunarak anlatılan bir hapishane gerçekliğinin ilk ve en önemli temsilcisi olarak Sabahattin Ali'nin nitelendirilmesi dikkat çekicidir.

Ünsal Akpak’ın “Sabah Yıldızı” başlı̆̆ıyla Sabahattin Ali’nin hayatını ve şahsiyetini yazması araştırmacıların işine yarayacak bilgi ve yorumlarla doludur. Yazarın "Refik Halit'in 'Memleket Hikâyeleri', Yakup Kadri'nin 'Yaban'inda yansıyan yanlı̧̧ ve yorumsuz Anadolu gerçeği, S. Ali ile değiştiğini görmekteyiz” (Akpak, 1973: 188) tespiti önemlidir. Asfalt Yol hikâyesinde geçen "Köy yaşıyan, çalı̧̧an bir mahlûktur ve bu koku onun ter kokusudur. Dünyada hiçbir koku beni bu kadar saramamı̧, kafamdan birbiri arkasına bu kadar hâtıralar yuvarlayıp geçirmemiştir”(Akpak, 1973: 189) ifadeleri bu görüşü destekler mahiyettedir.

Necati Mert, S. Ali'de taklitçiliğin görülmediğinden bahseder. Onun eserlerindeki kahramanların düz duvar önünde "icrayı sanat" eden gölgeler olmaktan çıkıp dört dörtlük karakterler düzeyine yükselmesi Marksist estetik kuramın bir gereği olarak siyasal, toplumsal, tinsel yaşam özelliklerinin hep ekonomik bağlantılarla verilmesine dayandırılmıştır (Mert, 1973: 194-195).

Derginin sonunda da Sabahattin Ali - Sait Faik dosyası açılmış, iki sanatçı farklı yazarlar tarafından farklı yönlerden karşılaştırılmıştır.

\section{Yansıma Dergisinde Nâzım Hikmet}

Yansımàda Sabahattin Ali gibi Nâzım Hikmet'e de ayrı bir ilgi gösterilmiş; derginin Haziran 1974 tarihli 30. sayısı "Nâzım Hikmet Özel Sayısı" olarak düzenlenmiştir. Altmış üç sayfadan müteşekkil bu sayıyla birlikte derginin diğer sayılarında Türk edebiyatının büyük şairlerinden Nâzım Hikmet ve eserleri üzerine inceleme, eleştiri, anı ve soruşturma yazılarına geniş yer verilmiştir. Ayrıca şair, şiir ve karikatürlerle de anlatılmıştır. Örneğin söz konusu özel sayının ön kapağında Nâzım Hikmet'in bir portresi, iç sayfalarda da Tekin Sönmez’in şair adına kaleme aldığı bir şiir vardır. "Nâzımlar Kalır Bu Dünyada” başlıklı bu şiir şöyledir:

$$
\begin{gathered}
\text { “... } \\
\text { hayatıyla să̆ar şiirini } \\
\text { her an tende taşı ölümü } \\
\text { ölümü börklüce kucakladığı gün } \\
\text { derim ki: NÂZIMLAR kalır bu dünyada } \\
\text { ăgıtı hiç söylenmeyen”(Sönmez, 1974: 347) }
\end{gathered}
$$


Yansımảda ayrıca, "Nâzım Hikmet İnceleme Yarı̧̧ası" düzenlenmiş ve sonuçları özel sayıda açıklanan bu yarışmaya göre birinciliğe değer bir yazı bulunmamıştır. Tankut Cantel'in "Nâzım Hikmet Şiiri” adlı incelemesi ile M. Erhan Ekici'nin "Nâzım Hikmet'in Dünya Görüşü ve Sanatı” başlıklı incelemesi arasında ikincilik paylaştırılmış; Ender Kâmil Boyacı'nın da "Nazizme ve Faşizme Karşı Nâzım Hikmet" başlıklı inceleme yazısı üçüncülüğe değer görülmüştür.

Yansıma’da Nâzım Hikmet'le ilgili bazı yazılar ve bu yazılardan kesitler şöyledir:

Aydın Sayman, "Nâzım Hikmet ve Sinema"da Nâzım Hikmet ve sinema ilgisini üç bölüm halinde ele almıştır. İlkinde Nâzım Hikmet'in sinema ile ilgili görüşlerinin neler olduğunu, ikinci bölümde Nâzım Hikmet'in sinema çalışmalarının kronolojik sıralamasını, son bölümde de Nâzım Hikmet’in şiirlerindeki sinemasal özelliklerin nasıl yansıdığını ifade eder. Sayman'ın deyimiyle Nâzım Hikmet'e göre sinema diğer birçok sanat dalının kaynaştığı, sınırsız olanaklara sahip ve halkla en yakın ilişki kurulabilecek sanat dalıdır. Asistanlıktan yönetmenliğe, senaryo yazarlı̆̆ına kadar Nâzım Hikmet'in sinema çalışmalarını kronolojik olarak veren Sayman, şairin şiirlerinin özellikle de destan niteliğinde olanların senaryo tekniğinden izler taşıdığını; böylelikle okuyucunun zihninde zaman ve mekân kavramları içinde birbirine bağlı devinimler gösteren sahneler ve görüntüler yarattığını ancak bunların tamamına "çevrim senaryo" yahut "özgün senaryo" denilemeyeceğini söyler. (Sayman, 1973: 145)

Tekin Sönmez, “Orhan Kemal'de Nâzım Hikmet Dönemeci” (1972: 8-9) başlıklı yazısıyla Orhan Kemal'in şiiri bırakıp hikâyeye yönelmesinde ve bu türde başarılı ürünler vermesinde Nâzım Hikmet'in yönlendirmesinin önemli bir payı olması üzerinde durur.

Yansımảnın 30. sayısı, otuzlar İtalyasından artakalmış gibi duran, Batı dünyasında artık izleri çoktan silinmiş ancak parlamenter sistemin devrimcileri yok etmek amacıyla çıkarttığı "fikir suçu”nun temelsizliğini ağır bir dille eleştiren “'Fikir Suçu' Diye Sürdürülen Olay”(Yansıma, 1974: 322) başlıklı yazı ile başlar. Nihat Behram'n “Acının Hain Bekçileri, Dinleyin” şiiri ile devam eder. Şiir dönemin siyasî baskılarına bir başkaldırı niteliğindedir ve sisteme meydan okuyucu bir üslûpla yazılmıştır:

\author{
“yarasalar, duaların, dolann ölümün artıkları \\ gün gelir kaplar sokaklarımızı da aydınlıklar \\ efendilerinizle birlikte yok olursunuz"(Behram, 1974: 323)
}

Tankut Centel'in "Nâzım Hikmet Siiri" (1974: 327-345) isimli yazısında ise şairin özellikle diyalektik materyalizm, tarihsel maddecilik ve marksist estetik kuramları çerçevesinde değerlendirildiği görülür. Bu yazı, Nâzım Hikmet’in şiirinin o güne değin eleştirmenler tarafından maksatlı olarak sadece biçimsel yönden değerlendirildiğini, Marksist estetik kurama ve sinıfsal temellere dayanmadan yapilan incelemelerin maksatlı olduğunu belirten bir önsözle başlar. Yazara göre onun şiiri gelecek toplumsal kuruluşun üst yapısını hazırlar; 
diyalektik maddecilik, tarihsel maddecilik ve bilimsel toplumculuk ilkelerine bağlıdır. Konu olarak diyalektik olması ezilme ve başkaldırı ile sömürü düzeninin sebep-sonuç ilişkisi içinde ele alınması demektir.

Nâzım'ın şiiri sürekli bir "devingenlik" içindedir, bu sebeple değiş̧ik evreler içinde çözümlenmelidir. Bunlar, ilk dönem Meşin Kaplı Kitap’a (1921) kadar, ikinci evre 1937’de soruşturmaya verdiği cevaba kadar, sonuncusu da Memleketimden İnsan Manzaralarìna kadar olan dilimdir. 1938'deki hüküm giymesinden sonra sesindeki coşkunun azalması meselesi tartışılmış ve şiirindeki bu değişim ayrıca ele alınmıştır. Nâzım’ı bu dönemde eleştirenler olmuştur (Mustafa Öneş, Zühtü Baytar, Naci Sadullah).

Tankut Centel, ilk dönemi idealizm ikinci ve üçüncü evreyi diyalektik kavramları ile tanımlar. Nâzım'ın diyalektiği Marks'ın maddeci diyalektiği ile örtüşür. Diyalektik, toplumsal olayları soyutlanıp parça olarak görmez; sürekli bir hareket içinde somut bir bütün şeklinde görür:

“-Her şey değişip akmada

bu hal beni hayran birakmada...”(s.332)

Maddenin sürekli değişim halinde oluşuna işaret çoğu zaman görülebilir:

"Sen ki topraksin, durup dinlenmeden değişirsin.”(s.332)

Marx, Kapitalde "İ̧̧ (çalışma), her şeyden önce, hem insanın hem doğanın birlikte katıldı̆̆ı... bir süreçtir... Dış âlem üzerinde etki yaparken ve onu değgiştirirken o, aynı zamanda kendi öz tabiatını da değiştirir. Böylece, kendisinin uyuklamakta olan güçlerini geliştirir”(Marx'tan Aktaran Cantel, 1974: 332) der.

Cantel, "Benerci Kendini Niçin Öldürdü?” de değişimin şu şekilde karşımıza çıktığını belirtir:

"Gebedir bir sükût bir yükselişe.

Ne mümkün karşı koymak

bu köpürmüs gelişe...”(s.333)

Nâzım Hikmet'in, "Sanat Telâkkisi" şiirinde (835 Satır) diyalektik materyalizmi nasıl ele aldığı görülebilir. Onun sanatına ilham veren "peri” değil maddi bir kanat şeklinde yorumladığ1 “asma köprülerin putrelleri”dir (Cantel, 1974: 336). ( Putrel, asma köprülerin dayandığ1 çelik kiriştir.)

Cantel (1974: 337)'e göre Plehanov, Marksist estetiği biçimlendirmeye çalışır. Marx’a göre güzellik, toplumun ekonomik olarak gelişmesine göre gelişir. Nâzım da aruz ve hecenin yıkılışını üstyapı ile ekonomik temel arasındaki uyumsuzluğa bağlar. Nâzım'ın şiiri, diyalektik 
maddeciliğin tarihsel çözümlemesini yapabildiği için kavga şiiridir, diye görenler de vardır (Lenin, 1970: 9).

Tankut Centel; "Makinalaşmak" şiirini yabancılaşmadan arınmış bir toplumun şiiri olarak ele almadığı ve tek bir şiiri ile Nâzım’ı çözümlemeye çalıştığı için yanlış yorumladığını iddia ederek Mehmet Kaplan'ı eleştirir.

Engels, gerçekliğii, ayrıntıların gerçekliği ve tipik durumlarda tipik kişilerin gerçeğe uygunluğu şeklinde tanımlar. Nâzım da gerçek sanatı hayatı yansıtan sanat olarak tanımlar. Ona göre toplumsal gerçeklik ümitsizliğge ve kötümserliğe yer vermez. Bu yönleriyle Sartre’a karşı çıkar ve Mayakovski'den de ayrilır (Cantel, 1974: 343-345).

Selahattin Hilav da çağın şairle şiirin birleştiği bir çağ; şiirin şaire, şairin şiire dönüştüğü bir çă̆ olduğunu iddia ederek, Nâzım'ı "Büyük şairdir ancak kişiliği bizi ilgilendirmez ve o bir efsanedir bir mittir, sanattaki başarısı kişisel serüvenine borçludur, yazdığ1 şiire değil..” diyenlerin gerçek manada onu anlamak ve anlatmaktan uzak, kısır bir anlayışı ifade ettiklerini belirtir (Hilav, 1974: 353).

Selahattin Hilav, az değinilmiş bir konuya da dikkat çeker: Nâzım sadece toplumcu bir şair değildir. Onun şiirinde kişiliğinin bir uzantısı olarak "toplumcu-ferdiyetçi” bir özellik göz ardı edilemez. Selahattin Hilav'n yorumuna göre bizde geleneksel olarak devlet kapıs1-adamı olmaktan kurtulamayan ve batı ferdiyetçiliğini sadece taklit edenler, gerçek ferdiyetçiliği anlayamamış ve gerçekleştirememiştir. Bu hususta Nâzım istisnadır. O, hem fert olmanın hem de toplum için sanat yapmanın dâhiliğini başarmıştır. Onun ferdiyetçiliği "yüksek bir moment içinde erimiş total insana yönelmiş toplumcu-ferdiyetçilik"tir (Hilav, 1974: 356).

Dergi 32. sayıda, Nâzım Hikmet inceleme yarışmasında derece alan yazarlara "İşçi sınıfı ideolojisi”nin şiirlerde yansıtılması ve bunu uygulayan şairlerin kimler olduğuna yönelik sorular sorar. Buradaki sorulardan biri Nâzım Hikmet'le ilgilidir ve devrimci Türk şiirine emek vermiş isimler denince Nâzım Hikmet'in genelde ilk sırada söylenmesinin doğal olup olmadığ1 ve diğer şairleri kendi yaşadıkları tarihsel süreç içerisinde değerlendirmenin uygun olup olmadığı sorulur. Bu sorulara yanıt veren M. Erhan Ekici ve Ender Kâmil Boyacı hemfikirdirler. Her iki isim de, Nâzım Hikmet'in Türk edebiyatında sosyalist realist akımın öncüsü olduğu, dolayısıyla ustalık onurunun ve ilk sıranın Nâzım Hikmet’in olduğu; diğer şairleri Nâzım Hikmet'le kıyaslamanın gereksiz olup onları içinde bulundukları tarihi dönemde davaya katkıları gereği eleştirmenin gerektiği düşüncesindedirler (Yansıma, 1974: 126-128).

Yansıma'da Sabahattin Ali ve Nâzım Hikmet ile ilgili yayınlanan yazıların künyelerini vermek gerekirse şu şekildedir:

\section{Sabahattin Ali İle İlgili Yazıların Künyeleri}

Nesin, Aziz (Mart 1973). “Son Anı”, Yansima, C. 2, S. 15, s. 144- 146/153. 
Kansu, Ceyhun Atuf (Mart 1973). "Şiirin Demirci Ustası", Yansıma, C. 2, S. 15, s. 154- 157.

Füruzan, “(Hanende Melek) Yeniden Okunurken”, Yansima, C. 2, S. 15 (Mart 1973), s. 163$165 / 193$.

Hulki Aktunç, “Orta Yerdeki Şeytan?”, Yansıma, C. 2, S. 15 (Mart 1973), s. 176- 180.

İbrahim İşyar, “<<Gramafon Avrat >> ile <<Ayten>>in Düşündürdükleri”, Yansıma, C. 2, S. 17, (Mayis 1973), s. 334- 335.

Kemal Ateş, "Sabahattin Ali'nin Eserlerinde Hapishane”, Yansima, C. 2, S. 15 (Mart 1973), s. $181-185$.

Mehmet Ergün, "Sabahattin Ali'nin Önemi", Yansıma, C. 2, S. 16, (Nisan 1973), s. 270278.

Mehmet Seyda, "Edebiyatımızda Sabahattin Ali- Sait Faik İkilemi ya da Ekmek mi Pasta mı? Sorunu”, Yansima, C. 2, S. 15 (Mart 1973), s. 147- 153.

Mehmet Veysel, “Sabahattin Ali'de Masal”, Yansima, C. 2, S. 15 (Mart 1973), s. 191- 193.

Mehmetcan Köksal, “Bir Süreç, Bir Yazar”, Yansıma, C. 2, S. 15 (Mart 1973), s. 130- 132.

Necati Mert, “Sabahattin Ali’nin Önemi”, Yansıma, C. 2, S. 15 (Mart 1973), s. 194- 195.

Ömer Faruk Toprak, "Usta”, Yansima, C. 2, S. 15 (Mart 1973), s. 158- 159.

Rifat Ilgaz, “25 Y1l Sonra”, Yansima, C. 2, S. 15 (Mart 1973), s. 134- 143.

Rıfat Ilgaz, "Eleştiricinin Ödüllendiriş ve Ceza Özgürlüğü”, Yansıma, C. 1, S. 41 (Mayıs 1975), s. 3- 7.

Said Maden, “Sabahattin Ali”, Yansima, C. 2, S. 15 (Mart 1973), s. 133.

Salih Yurttaş, "Sabahattin Ali Gerçekçiliğine Giriş", Yansıma, C. 2, S. 15 (Mart 1973), s. 196- 198.

Şükran Kurdakul, "Sabahattin Ali ve Varlık Dergisi”, Yansıma, C. 2, S. 15 (Mart 1973), s. $160-162$.

Tekin Sönmez, “Sınıflı Toplumlarda Analık Hukuku 'Ayran' ve 'Kağnı”, Yansıma, C. 2, S. 15 (Mart 1973), s. 166- 171.

Ünsal Akpak, “Sabah Yildız”, Yansima, C. 2, S. 15 (Mart 1973), s. 186- 190.

Yansıma, "Sabahattin Ali- Sait Faik Üzerine”, Yansıma, C. 2, S. 15 (Mart 1973), s. 210- 224.

Yansıma, “Sabahattin Ali Üzerine”, Yansima, C. 2, S. 15 (Mart 1973), s. 205 - 209.

Zühtü Bayar, "Türk Hikâyeciliğinin Büyük Dönemeci: Sabahattin Ali”, Yansıma, C. 2, S. 15 (Mart 1973), s. 172- 175.

\section{Nâzım Hikmet İle İlgili Yazıların Künyeleri}

Hatipoğlu, Aydın (Haziran 1974). “Anılardan”, Yansıma, C. 1, S. 30 (Haziran 1974), s. 380381.

Sayman, Aydın (Haziran 1973). "Nâzım Hikmet ve Sinema”, Yansıma, C. 3, S. 18, s. 144148. 
Balaban, "Şair Baba Sureti”, Yansıma, C. 1, S. 30 (Haziran 1974), s. 357- 363.

Blas de Otero, "Nâzım Hikmet'e Şiirler ve Mektuplar", (Çev: G. Uçkan), Yansıma, C. 1, S. 42 (Haziran 1975), s. 15- 16.

Ceyhun Atuf Kansu, “Ozanın Adı”, Yansima, C. 1, S. 30 (Haziran 1974), s. 368- 369.

Ender Kâmil Boyacı, "Faşizm’e ve Nazizm’e Karşı Nâzım Hikmet”, Yansıma, C. 2, S. 32 (Ağustos 1974), s. 82- 125.

Hasan Gürkan, "Saman Sarısı Üstüne Notlar”, Yansıma, C. 2, S. 35 (Kasım 1974), s. 351352.

Hikmet Altınkaynak, "Nâzım Hikmet’in Masalları", Yansıma, C. 1, S. 30 (Haziran 1974), s. 373- 375.

M. Erhan Ekici, "Nâzım Hikmet’in Dünya Görüşü ve Sanatı", Yansıma, C. 2, S. 31 (Temmuz 1974), s. 8- 29.

Mustafa Öneş, "Nâzım Hikmet’in Rubaileri Üzerine Notlar", Yansıma, C. 3, S. 18 (Haziran 1973), s. 70- 71.

Mücahit Gültekin, "Memleketimden İnsan Manzaraları'nda Mizah”, Yansıma, C. 2, S. 33 (Eylül 1974), s. 181- 188.

Nâzım Hikmet, "Karar Günleri”, Yansıma, C. 4, S. 24 (Aralık 1973), s. 326.

Nâzım Hikmet, "Şiir Üstüne”, Yansıma, C. 3, S. 18 (Haziran 1973), s. 5-7.

Rifat Ilgaz, “25 Y1l Sonra”, Yansima, C. 2, S. 15 (Mart 1973), s. 134- 143.

Rıfat Ilgaz, "Ölülerimizi Andıkça”, Yansıma, C. 1, S. 30 (Haziran 1974), s. 365- 367.

Selahattin Hilav, "Son Sanat Tartışmaları Nâzım Hikmet Estetler ve Sosyoloji”, Yansıma, C. 1, S. 30 (Haziran 1974), s. 348- 356.

Tankut Centel, "Nâzım Hikmet Şiiri", Yansıma, C. 1, S. 30 (Haziran 1974), s. 327- 345/ 382- 384.

Tekin Sönmez, "Nâzımlar Kalır Bu Dünyada”, Yansıma, C. 1, S. 30 (Haziran 1974), s. 347.

Tekin Sönmez, "Orhan Kemal'de Nâzım Hikmet Dönemeci”, Yansima, C. 1, S. 6 (Haziran 1972), s. 8- 9.

Yansima, “Anıyoruz”, Yansima, C. 1, S. 30 (Haziran 1974), s. 364.

Yansıma, “Anıyoruz”, Yansima, C. 1, S. 6 (Haziran 1972), s. 160.

Yansıma, "Nâzım Hikmet İnceleme Yarışması Sonuçları", Yansıma, C. 1, S. 30 (Haziran 1974), s. 326.

Yansıma, "Nâzım Hikmet İnceleme Yarışmasını Kazanan Yazarlara Sorular", Yansıma, C. 2, S. 32 (Ağustos 1974), s. 126- 128.

Zühtü Bayar, "Nâzım Hikmet’in Oyun Yazarlı̆̆ı", Yansıma, C. 1, S. 30 (Haziran 1974), s. 370- 372 . 


\section{Sonuç}

12 Mart Muhtırasının ardından yaklaşık on ay sonra yayına başlayan Yansıma dergisi, 45 sayılık yayın sürecinde dönemin önde gelen kalemlerine ev sahipliği yapmıştır. Sanat amacı güderek kültürün taşıyıcılığını üstlendiğini ileri süren dergi, çeşitli konularda önemli çalı̧̧malar neşretmiştir. Dergi, toplumcu gerçekçi edebiyata ve bu edebiyatın sanatçılarına ayrı bir ilgi göstermiştir. Nitekim bu ilgi Nâzım Hikmet ve Sabahattin Ali'de yoğunluk kazanmıştır.

Toplumcu gerçekçi edebiyatın temsilcilerinden sayılan Nâzım Hikmet ve Sabahattin Ali, kendi dönemlerinden bu yana birçok sanatçı için öncü kabul edilmiştir. Gerek düşünceleri gerekse eserleriyle etkileri günümüzde de devam etmektedir. Bundan dolayı Yansıma da Sabahattin Ali ve Nâzım Hikmet için ayrı ayrı özel sayı düzenlemiştir.

Yansıma dergisinin Nâzım dosyasını açtığı 30. sayının başyazısında mevcut düzenin devrimcileri köşeye sıkıştırmak maksatlı, mecliste fikir özgürlüğüne aykırı kanun yapılmasına dikkat çekilmesi, derginin ideolojik olarak durduğu yeri gösterir. Hemen akabinde Nihat Behram'ın sisteme meydan okur bir başkaldırıyı tema olarak işleyen şiiri, ideolojinin şiirle desteklenmesinin bir ifadesidir.

Nâzım’la ilgili yazıların daha çok estetik kuram çerçevesinde ele alınması belirgindir. Onun şiirini hümanist çizgiden bilimsel sosyalizme, diyalektik materyalizmden kavgacı şiire, hatta 1938'den sonra da coşkusunu yitirmiş şiire kadar geniş bir yelpaze içinde değerlendirenler olmuştur. Bu manada derginin şiire ve sanata gösterdiği ilgiyi görmek mümkündür.

Sabahattin Ali özel sayısı ise tamamen edebiyat ve sanat merkezli ele alınmıştır. Sabahattin Ali’nin özellikle toplumcu gerçekçilik içinde yeri belirginleştirilmeye çalı̧ıllmıştır. Sabahattin Ali’nin geleneksel tahkiyenin özelliklerini barındıran hikâyeleri olduğu vurgusunun yapıldığ1 yazılar da görülür. Sanatçının hikâyeleri genel olarak toplumcu kuramlarla tahlil edilmeye çalış1lmıştır. Sabahattin Ali’nin daha dışa dönük, Sait Faik’in ise daha içe dönük bir estetik anlayışa sahip olduklarını anlatan dosyada da iki hikâyeci ele alınmış ve karşılaştırılmıştır.

Yansıma, sayfalarında gerek Sabahattin Ali gerekse Nâzım Hikmet için bu denli geniş bilgilere yer vererek her iki yazarın da hayatı, sanatı ve edebî şahsiyeti hakkında kapsamlı birer biyografi örneği sunmuştur, denilebilir.

\section{Kaynaklar}

AKPAK, Ünsal (Mart 1973). "Sabah Yıldız”, Yansıma, Y.2, C.2, S.15, s.186-190.

AKTUNÇ, Hulki (Mart 1973). “Orta Yerdeki Şeytan”, Yansıma, Y.2, C.2, S.15, s.176-180.

BEHRAM, Nihat (Haziran 1974), “Acının Hain Bekçileri”, Yansıma, Y.3, C.1, S.30, s.323324.

CANTEL, Tankut (Haziran 1974), "Nâzım Hikmet Şiiri”, Yansıma, Y.3, C.1, S.30, s.327345.

Füruzan (Mart 1973), “Hanende Melek Yeniden Okunurken”, Yansima, Y.2, C.2, S.15, s.163-165/193. 
HİLAV, Selahattin (Haziran 1974), "Son Sanat Tartışmaları Nâzım Hikmet Estetler ve Sosyoloji”, Yansima, Y.3, C.1, S.30, s.348-356.

ILGAZ, Rifat (Mart 1973), "25 Y11 Sonra”, Yansıma, Y.2, C.2, S.15, s.134-143.

KANSU, Ceyhun Atuf (Mart 1973), “Şiirin Demirci Ustası”, Yansıma, Y.2, C.2, S.15, s.154157.

KÖKSAL, Mehmetcan (Mart 1973), “Bir Süreç, Bir Yazar”, Yansıma, Y.2, C.2, S.15, s.130132.

KURDAKUL, Şükran (Mart 1973), "Sabahattin Ali ve Varlık Dergisi”, Yansıma, Y.2, C.2, S.15, s.160-162.

LENIN, Vladimir Ilyiç (1970), Sosyalizm ve Savaş, (Çev: N. Solukçu), Sol Yayınları, Ankara.

MERT, Necati (Mart 1973), "Sabahattin Ali'nin Önemi”, Yansıma, Y.2, C.2, S.15, s.194195.

SEYDA, Mehmet (Mart 1973), "Edebiyatımızda Sabahattin Ali- Sait Faik İkilemi ya da Ekmek mi Pasta mi? Sorunu", Yansima, Y.2, C.2, S.15, s.147-153.

SÖNMEZ, Tekin (Haziran 1974), "Nâzımlar Kalır Bu Dünyada", Yansıma, Y.3, C.1, S.30, s.347.

SÖNMEZ, Tekin (Mart 1973), “Sınıflı Toplumlarda Analık Hukuku 'Ayran' ve 'Kağnı' ”, Yansima, Y.2, C.2, S.15, s.166-171.

Yansıma (Haziran 1974), “'Fikir Suçu' Diye Sürdürülen Oyun”, Yansıma, Y.3, C.1, S.30, s.322. 